\title{
The UK campaign on folic acid and flour fortification Andrew Russell*
}

\author{
Address: ASBAH House, 42 Park Road, Peterborough, Cambridgeshire, PE1 2UQ, UK \\ Email: Andrew Russell* - andrewr@asbah.org \\ * Corresponding author
}

\author{
from 50th Annual Meeting of the Society for Research into Hydrocephalus and Spina Bifida \\ Cambridge, UK. 30 August - 2 September 2006 \\ Published: 21 December 2006 \\ Cerebrospinal Fluid Research 2006, 3(SuppI I):S33 doi:I0.II86/I743-8454-3-SI-S33
}

(c) 2006 Russell; licensee BioMed Central Ltd.

\section{Background}

Following the UK Medical Research Council's (MRC) international study of folic acid and neural tube defects (NTD) reported in 1991, the mandatory fortification of flour as a population measure to reduce NTD pregnancies has been adopted by several nations. However, no European Union state has yet introduced fortification. A key policy outcome, arising from important research, is therefore still to be achieved. Factors, which militate against fortification, include exaggeration of risk, cultural opposition to "mass medication", political and administrative inertia, and the perception that NTDs are no longer an important health issue. ASBAH has been campaigning for over10 years in the UK, and a policy movement towards mandatory fortification may now be apparent.

\section{Materials and methods}

The campaign's story is outlined, from the MRC's groundbreaking results, through the recommendation in favour of flour fotification by the Committee on Medical Aspects of Nutrition (COMA), and the UK-wide health education campaign on folic acid, to the refusal of the Food Standards Agency (FSA) to recommend fortification in 2003, and a possible change of heart in 2006.

The cases for and against fortification are summarised, including the significant fall in NTD pregnancies in nations that have fortified, and the allegation that folic acid might 'mask' anaemia symptoms in older people with vitamin B12 deficiency. Meanwhile, over 1,200 NTD pregnancies are continuing to occur annually in the UK.
ASBAH's activities have included lobbying politicians, enlisting the support of experts and organisations, seeking media publicity, and liaising with key government agencies.

\section{Results}

The question of folic acid flour fortification is currently back with the Food Standards Agency for decision, and ASBAH's hope is that a positive decision by government will result.

\section{Conclusion}

Close links between experts, researchers and the voluntary sector can result in powerful lobbying efforts to put research progress into effect in public health policy. However, opposition from special interest groups, poorlyinformed media, and the inertia of politicians, should not be underestimated. 